\title{
Disparities in air pollution exposure in the United States by race-ethnicity and
} income, $1990-2010$

3
Jiawen Liu, ${ }^{1}$ Lara P. Clark, ${ }^{1}$ Matthew Bechle, ${ }^{1}$ Anjum Hajat, ${ }^{2}$ Sun-Young Kim,${ }^{3}$ Allen L. Robinson, ${ }^{4}$ Lianne Sheppard, ${ }^{5,6}$ Adam A. Szpiro, ${ }^{5}$ Julian D. Marshall ${ }^{1}$

${ }^{1}$ Department of Civil \& Environmental Engineering, University of Washington, Seattle, Washington, USA

${ }^{2}$ Department of Epidemiology, University of Washington, Seattle, Washington, USA

${ }^{3}$ Department of Cancer Control and Population Health, Graduate School of Cancer Science and Policy, National Cancer Center, Goyang-si, Gyeonggi-do, Korea

${ }^{4}$ Department of Mechanical Engineering \& Department of Engineering and Public Policy, Carnegie Mellon University, Pittsburgh, Pennsylvania, USA

${ }^{5}$ Department of Biostatistics, University of Washington, Seattle, Washington, USA

${ }^{6}$ Department of Environmental and Occupational Health Sciences, University of Washington, Seattle, Washington, USA

Please address correspondence to J.D. Marshall, Dept. of Civil \& Environmental Engineering, University of Washington, 201 More Hall, Seattle, WA, 98195, USA. Telephone: (206) 6852591.Email: jdmarsh@uw.edu

Declaration of competing financial interests: All authors declare they have no actual or potential competing financial interest. 


\section{Abstract}

27 Background: Few studies have investigated air pollution exposure disparities by race-ethnicity 28 and income across criteria air pollutants, locations, or time.

Objectives: To quantify exposure disparities by race-ethnicity and income, throughout the contiguous US, for six criteria air pollutants, during 1990 to 2010.

Methods: We quantified exposure disparities among racial-ethnic groups (non-Hispanic White, non-Hispanic Black, Hispanic (any race), non-Hispanic Asian) and by income for multiple spatial units (contiguous US, states, urban vs. rural areas) and years $(1990,2000,2010)$ for carbon monoxide $[\mathrm{CO}]$, nitrogen dioxide $\left[\mathrm{NO}_{2}\right]$, ozone $\left[\mathrm{O}_{3}\right]$, particulate matter $\left[\mathrm{PM}_{2.5}, \mathrm{PM}_{10}\right]$, and sulfur dioxide $\left[\mathrm{SO}_{2}\right]$. We used decennial census data for demographic information and a national empirical model for ambient air pollution levels.

Results: For all years and pollutants, the racial-ethnic group with the highest national average exposure was a racial-ethnic minority group. In 2010, the disparity between the racial-ethnic group with the highest versus lowest national-average exposure was largest for $\mathrm{NO}_{2}(64 \%$ [ 4.6 ppb]), smallest for $\mathrm{O}_{3}(4 \%$ [1.6 ppb]), and intermediate for the remaining pollutants (13\%-21\%). The disparities varied by US state; for example, for $\mathrm{PM}_{2.5}$ in 2010, exposures were at least 5\% higher-than-average in 63\% of states for non-Hispanic Black populations, in 33\% and 26\% of states for Hispanic and for non-Hispanic Asian populations, respectively, and in no states for non-Hispanic White populations. Absolute exposure disparities were larger among racial-ethnic groups than among income categories (range among pollutants: between 1.1 and 21 times larger). Over study period, national absolute racial-ethnic exposure disparities declined by between 35\% (0.66 $\left.\mu \mathrm{g} \mathrm{m}^{-3} ; \mathrm{PM}_{2.5}\right)$ and $88 \%$ (0.35 ppm; CO).

Discussion: As air pollution concentrations declined during 1990 to 2010, racial-ethnic exposure disparities also declined. However, in 2010, racial-ethnic exposure disparities remained across income levels, in urban and rural areas, and in all states, for multiple pollutants. 
Air pollution is associated with $\sim 100,000$ annual premature deaths in the United States (Stanaway et al. 2018) and is linked to cardiovascular disease, respiratory disease, cancers, adverse birth outcomes, cognitive decline, and other health impacts (Cohen et al. 2017; Darrow et al. 2019; Lelieveld et al. 2015; Paul et al. 2019; Pope et al. 2009; Rivas et al. 2019; Stieb et al. 2012; Underwood 2017). Air pollution, and its associated health impacts, is not equitably distributed by race-ethnicity or income. Previous research has documented higher-than-average air pollution exposures for racial-ethnic minority populations and lower-income populations in the US (Brulle and Pellow 2006; Evans and Kantrowitz 2002; Mohai et al. 2009), leading to disparities in attributable health impacts (Bowe et al. 2019; Fann et al. 2019; Gee and PayneSturges 2004). Most investigations of disparities in air pollution exposure involve a single pollutant, location, and/or time-point (Hajat et al. 2015; Marshall et al. 2014). Evidence from more comprehensive investigations suggests that exposure disparities by race-ethnicity and/or income can vary by pollutant (Rosofsky et al. 2018), location (e.g., by state (Bullock et al. 2018; Salazar et al. 2019), urbanicity (Mikati et al. 2018), metropolitan area (Zwickl et al. 2014; Downey et al. 2008)), and time-point (Ard 2015; Clark et al. 2017; Kravitz-Wirtz et al. 2016; Colmer et al. 2020). However, broad patterns in exposure disparities have not yet been national population.

The objective of our research was to comprehensively and consistently investigate disparities in exposure to Environmental Protection Agency (EPA) criteria air pollutants for the two decades following the 1990 Clean Air Act Amendments in the US. Specifically, we investigated the following questions regarding disparities in exposure to six criteria air pollutants: (1) How do exposures vary by race-ethnicity and income? (2) How do racial-ethnic exposure disparities vary by pollutant? (3) How do racial-ethnic exposure disparities vary by location (state, urban vs. rural areas)? (4) How have racial-ethnic exposure disparities changed over time? To address these questions, we combined demographic data from the US Census (Manson et al. 2019) with predictions of outdoor average levels of six criteria air pollutants from a publicly-available national empirical model derived from satellite, measurement and other types of data (Kim et al. 2020) at the spatial scale of census block groups and census tracts. We then analyzed disparities in exposure to six criteria air pollutants (all criteria air pollutants except lead $[\mathrm{Pb}]$; i.e., carbon monoxide $[\mathrm{CO}]$, nitrogen dioxide $\left[\mathrm{NO}_{2}\right]$, ozone $\left[\mathrm{O}_{3}\right]$, fine and coarse particulate matter $\left[\mathrm{PM}_{2.5}, \mathrm{PM}_{10}\right]$, and sulfur dioxide $\left[\mathrm{SO}_{2}\right]$ ) by race-ethnicity (four racial-ethnic groups: white, Black, Hispanic, Asian) and income (16 household income categories) across time-points (decennial census years: 1990, 2000, and 2010) and spatial units (contiguous US, state, urban vs. rural areas).

\section{Methods}

\section{Demographic and Air Pollution Datasets}

We obtained demographic data (i.e., population estimates by race-ethnicity, household income, and household income disaggregated by race-ethnicity) and map boundaries (e.g., states, census tracts, and census block groups) for the contiguous US from the 1990, 2000, and 2010 decennial census from the IPUMS National Historic Geographic Information System (NHGIS) (Manson et al. 2019).

NHGIS provides, for each census block group, and for 1990, 2000, and 2010 (standardized to 2010 spatial boundaries), population estimates for six census self-reported racial 
groups: (i) White alone, (ii) Black or African American alone, (iii) American Indian and Alaska

110 Native alone, (iv) Asian and Pacific Islander alone, (v) some other race alone, and (vi) two or

111 more races. NHGIS reports population estimates for two census self-reported ethnic groups: (i)

112 Hispanic or Latino and (ii) not Hispanic or Latino. Thus, there are 12 racial-ethnic groups in

113 NHGIS (six racial groups, two ethnic groups). Our main analyses here regarding racial-ethnic

114 exposure disparities included the four largest racial-ethnic groups, which in total covered 307

115 million people (97.2\% of the population) in the contiguous US in 2010: (i) not Hispanic or

116 Latino, White alone (64\% of the population; hereafter, "non-Hispanic White"), (ii) Hispanic or

117 Latino of any race(s) (16\%; hereafter, "Hispanic"), (iii) not Hispanic or Latino, Black or African

118 American alone (12\%; hereafter, "non-Hispanic Black"), and (iv) not Hispanic or Latino, Asian and Pacific Islander alone (4.6\%; hereafter, "non-Hispanic Asian”).

For analyses by income in 2010, we used 2010 NHGIS household income estimates. For each block group, NHGIS reports the number of households in 16 annual household income categories (total covered in 2010: 114 million households): $<10 \mathrm{k}, 10 \mathrm{k}-15 \mathrm{k}, 15 \mathrm{k}-20 \mathrm{k}, 20 \mathrm{k}-25 \mathrm{k}$, $25 \mathrm{k}-30 \mathrm{k}, 30 \mathrm{k}-35 \mathrm{k}, 35 \mathrm{k}-40 \mathrm{k}, 40 \mathrm{k}-45 \mathrm{k}, 45 \mathrm{k}-50 \mathrm{k}, 50 \mathrm{k}-60 \mathrm{k}, 60 \mathrm{k}-75 \mathrm{k}, 75 \mathrm{k}-100 \mathrm{k}, 100 \mathrm{k}-125 \mathrm{k}$, $125 \mathrm{k}-150 \mathrm{k}, 150 \mathrm{k}-200 \mathrm{k}$, and >200k (2010 inflation-adjusted US dollars).

For analyses by income disaggregated by race-ethnicity in 2010, data from the 2010 NHGIS were available at the census tract level. For each census tract, NHGIS reports the number of census householders in each of the 16 census income categories, disaggregated in eight census racial and/or ethnic groups: (i) not Hispanic or Latino, White alone, (ii) Black or African American alone, (iii) American Indian and Alaska Native alone, (iv) Asian alone, (v) Native Hawaiian and Other Pacific Islander alone, (vi) some other race alone, (vii) two or more races, and (viii) Hispanic or Latino. To best match demographic variables used in race-ethnicity analysis at the census block group level, we reported results for four largest race-ethnicity groups (total covered in 2010: 113 million census householders, 98.5\% of householders with data on income by race-ethnicity): not Hispanic or Latino, White alone (71\% of householders; hereafter, "non-Hispanic White"), Hispanic or Latino (12\%; hereafter, "Hispanic"), Black or African American alone (12\%; hereafter, "Black"), and Asian alone (3.8\%; hereafter, "Asian"). Thus, for the data used for the household income by race-ethnicity analysis (but not for other analyses), Black and Asian categories included both Hispanic and non-Hispanic individuals; for these analyses (but not others), Hispanic Black populations ( $0.40 \%$ of the population) would be included in results for Hispanic and for Black populations, and Hispanic Asian populations $(\sim 0.08 \%)$ would be included in results for Hispanic and for Asian populations. Additionally, for the data used for the household income by race-ethnicity analysis (but not for other analyses), the Asian category does not also include Pacific Islander populations.

The US Census Bureau defined census blocks as "urban" or "rural", based on population density and other characteristics (Ratcliffe et al. 2016). We used 2010 census urban/rural block definitions to define a 2010 census block group for all three years (1990, 2000, and 2010) as rural if all blocks inside it were rural, and we defined the remaining block groups as urban.

Average estimates of ambient air pollution levels for US EPA criteria pollutants were obtained from Center for Air, Climate, and Energy Solutions (CACES) empirical models for the contiguous US (www.caces.us/data). These models incorporate satellite-derived estimates of air pollution, satellite-derived land cover data, land use data, EPA monitoring station data, and universal Kriging (Kim et al. 2020); estimated pollution levels were available by census block at block centroids based on 2010 census boundaries for years from 1990 to 2010 for all pollutants except $\mathrm{PM}_{2.5}$ (for which monitoring data and exposure models were only available starting in 
1999). Estimated levels of $\mathrm{O}_{3}$ from the CACES empirical model are 5-month summer averages (specifically, the average during May through September of the daily maximum 8-hour moving average level); for remaining pollutants, estimated levels are annual averages.

CACES model performance during the years studied here (1990, 2000, 2010), as measured by cross-validated $\mathrm{R}^{2}$, was $0.84-0.89$ for $\mathrm{NO}_{2}$ and $\mathrm{PM}_{2.5}, 0.62-0.82$ for $\mathrm{O}_{3}, 0.56-0.62$ for $\mathrm{PM}_{10}$, and $0.32-0.66$ for $\mathrm{SO}_{2}$ and $\mathrm{CO}$ (Kim et al. 2020). Mean error (ME) across the census years studied was between -0.02 and $0 \mathrm{ppm}$ for $\mathrm{CO},-0.04$ to $0 \mathrm{ppb}$ for $\mathrm{O}_{3},-0.09$ to $-0.06 \mathrm{ppb}$ for $\mathrm{PM}_{2.5}$. Mean bias (MB) was $13 \%-22 \%$ for $\mathrm{SO}_{2}$, and $<10 \%$ for the other pollutants.

\section{Combining Demographic and Air Pollution Data}

We matched the CACES empirical model results and the Census demographic data using the 2010 census spatial boundary definitions (from finest to coarsest spatial resolution: block, block group and tract boundaries) for the three census years $(1990,2000,2010)$. We matched census block-level CACES model predictions for criteria air pollutants (blocks in 2010 in the contiguous US: $n=\sim 7$ million; average: $\sim 44$ residents per block) to census block group-level demographic data (block groups: $n=\sim 22,000 ; \sim 1400$ residents per block group) by calculating population-weighted mean air pollution levels for all census block centroids in that census block group using census block population data in year 2010. Similarly, to match census tract-level demographic data (tracts: $n=\sim 74,000 ; \sim 4200$ residents per tract), we calculated the populationweighted mean air pollution levels for all census block groups located within that tract.

\section{Estimating Exposures to Pollutants}

We estimated annual pollutant-specific exposures for 1990, 2000, and 2010 based on populationweighted mean predicted ambient air pollution levels for each demographic group (raceethnicity, income, and income by race-ethnicity; additional groups described in the Supplemental Material $[\mathrm{SM}]$ ). This approach (average ambient air pollution level at residential census block group or tract) is broadly consistent with many examples in research and practice, including EPA monitors, the National Ambient Air Quality Standards, many influential epidemiological studies, and the published empirical models employed here. This article focuses on pollution level disparities rather than health outcomes. We used the finest publicly available census spatial boundary data to estimate exposures for each analysis (income by race-ethnicity: tracts; all other analyses: block groups) based on availability of census demographic data.

The national annual (for $\mathrm{O}_{3}, 5$-month average; for remaining pollutants, annual-average) exposure for demographic group $i\left(e_{i}\right)$ was calculated for a given pollutant and year as:

$$
e_{i}=\frac{\sum_{j=1}^{n} c_{j} \mathrm{p}_{\mathrm{ij}}}{\sum_{j=1}^{n} p_{i j}},
$$

where $c_{j}$ is the predicted average ambient pollution level for block group or tract $j, p_{i j}$ is the population of demographic group $i$ in block group or tract $j$, and $n$ is the number of block groups or tracts in the analyzed spatial level (contiguous US, 49 "states" (defined as the District of Columbia plus 48 states), urban vs. rural areas).

\section{National Exposure Disparities Analyses}

Our primary exposure disparity metrics are based on absolute and relative differences in mean pollution levels. We selected metrics based on mean pollution levels for consistency with our focus on broad national average patterns in exposure disparities among multiple pollutants. 
Absolute disparity metrics are often connect to pollutant-specific health impacts(Harper et al. 2013). Relative disparity metrics (e.g., ratios, relative percent differences) are relevant for quantifying disproportionality in exposure burdens, in a way that can be compared or summarized among different pollutants. An important limitation of these metrics (based on differences in mean exposures) is that they do not include information about disparities across the full exposure distributions (Harper et al. 2013). To address this limitation, we conducted supplemental analyses using inequality metrics accounting for full exposure distributions (Gini Coefficient and between-group Atkinson Index), as described in the SM, as well as sensitivity analyses comparing metrics based on other specific points of the exposure distribution (i.e., comparing specific exposure percentiles) as described below.

We calculated the absolute and relative exposure disparity metrics using two different approaches nationally: (1) by race-ethnicity group and/or income category (i.e., the unit of analysis is a national subpopulation defined by race-ethnicity and/or income), and (2) by local demographic characteristics (i.e., the unit of analysis is a set of census block groups defined based on proportion of racial-ethnic minority residents).

\section{National Exposure Disparity Metrics Based on Racial-Ethnic Group and/or Income Category}

Our primary absolute disparity metric for quantifying national racial-ethnic exposure disparities is the pollutant-specific absolute difference in population-weighted average pollution level, as calculated using Equation (1) with block group level data, between the racial-ethnic group with the highest national mean exposure ("most-exposed group") and the racial-ethnic group with the lowest national mean exposure ("least-exposed group") among the four racialethnic groups (non-Hispanic White, non-Hispanic Black, non-Hispanic Asian, Hispanic); here, the unit of analysis is a racial-ethnic group. Our relative exposure disparity metric is the pollutant-specific exposure ratio, calculated as the ratio in population-weighted average pollution level between the most- and least-exposed racial-ethnic group. Both the absolute and relative exposure disparity metrics are constructed based on differences between most and least exposed racial-ethnic groups, to provide a measure of overall racial-ethnic disparities that avoids preselecting two specific groups for comparison and accounts for exposure disparities across multiple groups, in a consistent way for each pollutant (accounting for potential differences in the most- and least-exposed racial-ethnic groups by pollutant). We also report averages in relative disparities across pollutants as a representation of overall average inequalities in exposure to multiple pollutants; not as a representation of inequalities in health risks, which are pollutant-specific and depend on absolute levels of pollution exposure.

To quantify national income-based exposure disparities we calculated the pollutantspecific absolute difference in population-weighted average pollution level, using Equation (1) with block group level data, between the lowest $(<\$ 10,000)$ and the highest $(>\$ 200,000)$ household income categories (of the 16 census categories). Additionally, as a relative disparity metric, we calculated the relative percent difference in mean exposures between the lowest and highest income categories. As a supplementary analysis, we calculated similar absolute and relative exposure disparity metrics between the income category containing the $25^{\text {th }}$ percentile $(\$ 20,000-25,000)$ and the $75^{\text {th }}$ percentile $(\$ 75,000-100,000)$ of the income distribution.

To quantify national exposure disparities by race-ethnicity and income, we first calculated the absolute difference in population-weighted average pollution level between the most- and least- exposed racial-ethnic group (among the four racial-ethnic groups, as above) 
within each of the 16 census income categories, and then averaged that income category-specific racial-ethnic exposure disparity across all 16 income categories, for each pollutant. In the analyses for both race-ethnicity and income, we used census data for householders to calculate exposures for the four racial-ethnic groups using Equation (1) with tract level data. Reflecting publicly available census data for racial-ethnic groups by income category, for this section only, the Black and Asian groups include Hispanic and non-Hispanic individuals, and the Asian group does not include Pacific Islander individuals. As a relative disparity metric, we divided the absolute exposure disparity metric by the national mean pollution level, for each of the pollutants.

\section{National Exposure Disparity Metrics Based on Local Demographic Characteristics (i.e., Block Group Bins by Proportion of Racial-Ethnic Minority Residents)}

We also investigated exposure disparities based on racial-ethnic minority resident percentages; here, the unit of analysis is bin of census block groups. Each block group bin was defined as single percentile (i.e., 1\%) of all block groups stratified by the proportion of racialethnic minority residents. There were approximately 215,000 block groups in 2010 , so each block group bin contained approximately 2,150 block groups. To investigate racial-ethnic disparities among block group bins, we rank ordered all census block group bins based on percent of a racial-ethnic minority residents (i.e., people self-reporting any race-ethnicity other than non-Hispanic White alone). For example, the first block group bin was the first percentile, and consisted of all block groups with between $0 \%$ and $0.67 \%$ racial-ethnic minority residents; the second block group bin was the second percentile, consisting of all block groups with $0.67 \%$ $-0.97 \%$ racial-ethnic minority residents; the third block group bin consisted of all block groups with $0.97 \%-1.2 \%$ racial-ethnic minority residents, and so on through all 100 block group bins. The last block group bin consisted of all block groups with 99\% - 100\% racial-ethnic minority residents. The annual exposure for demographic group $i$ for the $p^{\text {th }}$ percentile census block group bin $\left(e_{i p}\right)$ was calculated for a given pollutant and year as:

$$
e_{i p}=\frac{\sum_{j=1}^{n_{p}} c_{j} p_{\mathrm{ij}}}{\sum_{j=1}^{n_{p}} p_{i j}},
$$

where $c_{j}$ is the average pollution level for block group $j, p_{i j}$ is the population of demographic group $i$ in block group $j$, and $n_{p}$ is the number of block groups in the $p^{\text {th }}$ percentile block group bin. The absolute disparity is calculated as the exposure difference between block groups with the highest- versus lowest- deciles of proportion racial-ethnic minority residents, and, similarly, the relative disparity is calculated as the exposure ratio between block groups with the highestversus lowest- deciles of proportion racial-ethnic minority residents.

\section{National Analysis of High-End Exposure Disparities in 2010}

To quantify racial-ethnic disparities at the highest exposure levels, we analyzed the racial-ethnic composition of census block groups above the $90^{\text {th }}$ percentiles of the average pollution level among all census block groups. This was done seperately for each pollutant. First, for each of the four largest racial-ethnic groups, we estimated the proportion of that group's national population that lived in a high exposure block group; here, our unit of analysis is a racial-ethnic group. This calculation reflects the proportion of a racial-ethnic group's total US population that lived in heavily polluted (above the $90^{\text {th }}$ percentile) block groups. We performed this calculation for each pollutant and each racial-ethnic group, using Equation (3). The second analysis, which was the converse of the first, investigated the racial-ethnic composition of block groups above the $90^{\text {th }}$ 
percentile for average pollution level. Here, our unit of analysis is all block groups above the $90^{\text {th }}$ percentile. This calculation reflects the demographics of only people that lived in heavily polluted block groups. We completed this calculation for each pollutant and each racial-ethnic group using Equation (4).

$$
\begin{aligned}
& \mathrm{a}_{\mathrm{i}}=\frac{\sum_{j=1}^{n} p_{i j}}{p_{\text {total_national }_{i}}} * 100 \% . \\
& \mathrm{b}_{\mathrm{i}}=\frac{\sum_{j=1}^{n} p_{i j}}{p_{\text {total_block group }}} * 100 \% .
\end{aligned}
$$

Here, $a_{\mathrm{i}}$ is the percent of racial-ethnic group $i$ living in a block group with concentration above the $90^{\text {th }}$ percentile for that pollutant, $p_{i j}$ is the population of group $i$ in census block group $j$, $p_{\text {total_national }}$ is the total population for group $i$ in the United States, $p_{\text {total_block group }}$ is the total population of census block groups above the $90^{\text {th }}$ percentile in the United States for that pollutant, $\mathrm{b}_{\mathrm{i}}$ is (when considering only the people counted towards $P_{\text {total_block group }}$ ) the percent of people who are in racial-ethnic group $\mathrm{i}$, and $n$ is the number of census block groups above the $90^{\text {th }}$ percentile.

To explore multi-pollutant aspects of high-end exposure, we investigated the proportion of the total US population living in census block groups that were above the 90th percentile for exposure to 0, 1, 2, 3, and 4+ pollutants, for each racial-ethnic group in 2010, using Equation (3).

\section{Sensitivity Analysis on Robustness of National Exposure Disparity Estimates}

We conducted three sensitivity tests to investigate the robustness of conclusions based on estimated exposure disparities. First, as a sensitivity test for conclusions based on comparisons of mean values for exposures between groups, we calculated disparities using different metrics of the exposure distribution $\left(10^{\text {th }}, 25^{\text {th }}, 50^{\text {th }}, 75^{\text {th }}, 90^{\text {th }}\right.$ percentiles $)$.

The remaining two sensitivity tests investigated whether conclusions here are robust to uncertainty in exposure model predictions. Specifically, in the second sensitivity test, we repeated the analysis of national mean exposures by racial-ethnic group, but for only the population living in a census block group with an EPA monitor in 2010. In this sensitivity test, we used the monitor observations directly as the exposure level, rather than modeling exposures. We then calculated Spearman rank-order correlation of relative disparities by pollutant (between the most- and least- exposed group) between base case and sensitivity test.

In the third sensitivity test, we compared the magnitude of uncertainties in the estimated racial-ethnic exposure disparities with the magnitude of the estimated racial-ethnic exposure disparities. To assess the potential impact of model error on racial-ethnic disparities, we first calculated population-weighted mean error (ME) for each racial-ethnic group, $k$, using Equation (5):

$$
M E_{k}=\frac{\sum_{\mathrm{i}=1}^{\mathrm{n}}\left(\mathrm{c}_{\mathrm{im}}-\mathrm{c}_{\mathrm{io}}\right) \mathrm{p}_{\mathrm{ik}}}{\sum_{\mathrm{i}=1}^{\mathrm{n}} \mathrm{p}_{\mathrm{ik}}},
$$

where $c_{i m}$ is the modeled average pollution level for block group $i, c_{i o}$ is the measured average pollution level across all reporting EPA monitors within census block group $i, p_{i k}$ is the population of demographic group $k$ in block group $i$, and $n$ is the total number of block groups with EPA monitors. The ME of disparity between two racial-ethnic groups $i$ and $j$ induced by the model was calculated as the difference between populated-weighted ME for the two racial-ethnic groups $i$ and $j$. Calculated uncertainties are based on comparison with EPA measured pollution level in 2010. We then calculated the ratio between the uncertainties in estimated racial-ethnic 
exposure disparities (calculated as the difference in population-weighted mean error between the most- and least- exposed racial-ethnic groups) and the estimated racial-ethnic disparities between the most- and least-exposed racial-ethnic groups.

\section{Counterfactual Sensitivity Analysis of Exposure Disparities by Race-ethnicity and Income}

To explore interactions between race-ethnicity and income in exposures and absolute exposure disparities, we performed two counterfactual sensitivity analyses for each pollutant in 2010.

First, we calculated exposures and exposure disparities by race-ethnicity after controlling for income (i.e., a counterfactual in which each racial-ethnic group has the same income distribution as the national income distribution). To do this, we start with exposure disaggregated by race-ethnicity and income, but then apply the national income distribution (rather than the group's true income distribution) to calculate the (counterfactual) average exposure for each racial-ethnic group (i.e., we held the income distribution the same for each racial-ethnic group). We then calculated the (counterfactual) racial-ethnic exposure disparity between the most- and least- exposed racial-ethnic groups.

Second, we conducted the converse analysis: we calculated exposures and exposure disparities by income after controlling for race-ethnicity (i.e., a counterfactual in which each income category has the same racial-ethnic distribution as the national racial-ethnic distribution). To do this, we apply the national racial-ethnic distribution (rather than that income category's true racial-ethnic distribution) to calculate the (counterfactual) average exposure for each income category (i.e., we held the racial-ethnic distribution the same for each income category). We then calculated the (counterfactual) income-based disparity between the lowest- and highest- income categories.

\section{Counterfactual Analysis of Migration}

We investigated whether changes in racial-ethnic exposure disparities over time were mainly attributable to changes in air pollution levels ("air pollution") or changes in where people lived (abbreviated as "migration", but also including immigration and other shifts in demographic patterns) as a sensitivity analysis. To do so, we employed two counterfactual scenarios (Clark et al. 2017) during two decades (1990 to 2000; 2000 to 2010). For each scenario and year, we calculated exposures for the four largest racial-ethnic groups for the contiguous US population using Equation (1) based on census block group data. We then calculated the absolute racialethnic exposure disparity between the most- and least-exposed racial-ethnic groups (referred to in this section as "disparity") for all pollutants with available data (i.e., all except $\mathrm{PM}_{2.5}$ in 1990). To analyze 1990 to 2000, we calculated the change in disparity attributable to air pollution changed from 1990 to 2000 levels, with demographics remained constant at 1990 values (counterfactual scenario A), and used 1990 air pollution levels with demographic data changed from 1990 to 2000 values (counterfactual scenario B). To estimate the separate contribution of changes in air pollution during 1990 to 2000, we divided the disparity-changes from counterfactual scenario A by the "true" calculated disparity-change between 1990 and 2000 (i.e., using 1990 air pollution levels with 1990 demographic data, and using 2000 air pollution levels with 2000 demographic data). Similarly, to estimate the separate contribution of migration during 1990 to 2000, we divided the disparity-changes from counterfactual scenario B by the "true" calculated disparity change between 1990 and 2000. Lastly, we used an analogous approach to analyze the next decade: 2000 to 2010 . 


\section{Exposure Disparities Comparison Metrics for States}

381 We investigated patterns in absolute exposure disparities among the 48 states of the contiguous 382 US plus the District of Columbia (DC) (hereafter, "states" refers to 48 states and DC, a total of 49 geographic units in state-level related calculations) using two metrics for racial-ethnic exposure disparity. First, we used Equation (6) to calculate a state-specific population-weighted disparity for each of the four racial-ethnic groups and the state average relative to the pollutant's national mean. Second, for each state, we used Equation (7) to calculate a normalized population-weighted disparity between two groups: all racial-ethnic minority groups combined, and the non-Hispanic White group. This metric has the advantage of consistently comparing, for each state, exposures between racial-ethnic minority populations and the majority racial-ethnic group population (non-Hispanic White, 64\% of the population). Lastly, we averaged both metrics across the six pollutants.

$$
\begin{aligned}
d 1_{r} & =\frac{e_{r}-e_{\text {state }}}{e_{\text {national }} .} \\
d 2_{r} & =\frac{e_{\text {minority }}-e_{N H-W h i t e}}{e_{\text {national }}} .
\end{aligned}
$$

For each state and pollutant, $d 1_{r}$ is the normalized population-weighted disparity for racialethnic group $\mathrm{r}, e_{r}$ is the average exposure for racial-ethnic group $\mathrm{r}$ in the state, $e_{\text {state }}$ is the average exposure for all people in the state, $e_{\text {national }}$ is the average exposure for all people in the contiguous United States, $e_{\text {minority }}$ is the average exposure for all racial-ethnic minority populations in the state, and $e_{\mathrm{NH}-W h i t e}$ is the average exposure for the non-Hispanic White population in the state.

\section{Results \\ National Exposure Disparities by Race-Ethnicity and Income in 2010}

\section{By Race-Ethnicity}

To investigate national disparities in exposure to criteria air pollution by race-ethnicity, we first compared national population-weighted mean exposures by US census self-reported race-ethnicity in 2010, the most recent decennial census year with available data. We first present results for differences among subpopulations (unit of analysis: racial-ethnic group), then we present differences among locations, depending on the proportion of each racial-ethnic group residents in that location (unit of analysis: census block groups binned by proportion of racialethnic minority residents).

Estimated national mean air pollution exposures were higher for all three racial-ethnic minority groups than for the non-Hispanic White group for four of the six criteria pollutants (CO, $\mathrm{NO}_{2}, \mathrm{PM}_{2.5}$, and $\mathrm{PM}_{10}$ ) (Table 1 and Fig. 1). Disparities between the most- and least-exposed racial-ethnic groups were largest for $\mathrm{NO}_{2}$ (absolute disparity: $4.6 \mathrm{ppb}$, relative disparity [ratio]: 1.6); intermediate for $\mathrm{SO}_{2}(0.29 \mathrm{ppb}, 1.2), \mathrm{PM}_{10}\left(3.0 \mu \mathrm{g} \mathrm{m}^{-3}, 1.2\right), \mathrm{CO}(0.044 \mathrm{ppm}, 1.1)$, and $\mathrm{PM}_{2.5}\left(1.2 \mu \mathrm{g} \mathrm{m}^{-3}, 1.1\right)$; and lowest for $\mathrm{O}_{3}(1.6 \mathrm{ppb}, 1.0)$. For all six pollutants, the most-exposed group was a racial-ethnic minority group: for $\mathrm{PM}_{2.5}$ and $\mathrm{SO}_{2}$, national mean exposures were highest for the non-Hispanic Black population; for $\mathrm{CO}, \mathrm{NO}_{2}$, and $\mathrm{O}_{3}$, the non-Hispanic Asian population; and for $\mathrm{PM}_{10}$, the Hispanic population. For $\mathrm{CO}, \mathrm{NO}_{2}, \mathrm{PM}_{2.5}$, and $\mathrm{PM}_{10}$, national mean exposures were lowest for non-Hispanic White population; for $\mathrm{O}_{3}$, Hispanic population; and for $\mathrm{SO}_{2}$, non-Hispanic Asian population. (Supplemental disparity and inequality metrics are presented in Fig. S10 and Tables S38-39). 
Sensitivity test on robustness of conclusions based on mean values showed that, for all pollutants, the rank-order (i.e., most- to least-exposed racial-ethnic group, among the four racialethnic groups) was consistent throughout the exposure distributions (Fig. 1). The remaining two sensitivity tests investigated whether conclusions here are robust to uncertainty in exposure model predictions. Results reveal that the conclusions are robust to exposure model uncertainty. Results for analyzing only the population living in a census block group with an EPA monitor in 2010 were essentially the same as results using exposure model predictions: the non-Hispanic White group was the least-exposed group on average for most pollutants $\left(\mathrm{CO}, \mathrm{NO}_{2}, \mathrm{PM}_{2.5}, \mathrm{PM}_{10}\right.$, and $\mathrm{O}_{3}$ ), and the relative disparities by pollutant (between the most- and least- exposed group on average) were highly-correlated (Spearman rank-order correlation between base case and sensitivity test: 0.89 ). The ratio between the uncertainties in estimated racial-ethnic exposure disparities and the estimated racial-ethnic disparities between the most- and least-exposed racialethnic groups were small: on average across the six pollutants, 0.0073 (if using absolute values of the ratio, 0.083$)$. The largest absolute ratio was $-0.17\left[\mathrm{O}_{3}\right]$ That result indicated that the uncertainty in the exposure model predictions was always small compared to the predicted racial-ethnic exposure disparities.

We also performed an analysis to determine whether average air pollution levels varied based on the racial-ethnic composition of a given census block group. For $\mathrm{CO}, \mathrm{NO}_{2}, \mathrm{PM}_{2.5}$, and $\mathrm{PM}_{10}$, average pollution levels were higher in census block groups with higher proportions of racial-ethnic minority residents (Fig. 2). For $\mathrm{O}_{3}$, estimated average levels were approximately equal across census block group bins, regardless of census block group racial-ethnic characteristics (Fig. 2). For $\mathrm{SO}_{2}$, estimated average levels were generally higher in census block group bins with the highest and lowest proportions of racial-ethnic minority residents (i.e., higher in more racially segregated census block groups) (Fig. 2). This approach also reveals that the disparities were much larger for $\mathrm{NO}_{2}$ than for other pollutants. The disparity in average air pollution levels between block groups with the highest- versus lowest- deciles of proportion racial-ethnic minority residents (block groups with $>88 \%$ vs. $<4 \%$ racial-ethnic minority residents) was larger for $\mathrm{NO}_{2}$ (absolute disparity: $9.4 \mathrm{ppb}$, relative disparity [ratio]: 3.1 ) than for other pollutants (relative disparity [ratio] range: $0.8-1.4$, median: 1.1 )

Lastly, we investigated racial-ethnic disparities in exposure to the highest air pollution levels. First, for each racial-ethnic group we calculated the proportion of people nationally who lived in a block group with air pollution levels above the $90^{\text {th }}$ percentile for each pollutant. Averaged across all pollutants, the proportion of people nationally who lived in those highestexposure block groups was: $9.6 \%$ for the overall population, $17 \%$ for the Hispanic population, $15 \%$ for the non-Hispanic Asian population, $12 \%$ for the non-Hispanic Black population, and $7.2 \%$ for the non-Hispanic White population. Next, we calculated the racial-ethnic composition of the block groups with air pollution levels above the $90^{\text {th }}$ percentile for each pollutant. Racialethnic minority populations were more likely than non-Hispanic White populations to live in a census block group with air pollution levels above the $90^{\text {th }}$ percentile for all pollutants (range: $1.1 \times$ to $4.1 \times$, median: $2.1 \times$ ) except $\mathrm{SO}_{2}(0.88 \times)$. Racial-ethnic minority populations were also disproportionately likely to live in a census block group having multiple pollutants with levels above the $90^{\text {th }}$ percentile. For example, the proportion of population living in a census block group with levels above the $90^{\text {th }}$ percentile for four or more criteria pollutants was $5.2 \%$ for the Hispanic population (3.6x the national population average proportion), $2.2 \%$ for the nonHispanic Asian population (1.5x the average), $1.9 \%$ for the non-Hispanic Black population (1.3× 
the average), and $0.36 \%$ for the non-Hispanic White population $(0.25 \times$ the average) (for comparison: $1.4 \%$ for the overall US population).

\section{By Income}

To investigate national exposure disparities by income, we first compared national mean exposures to criteria air pollution by census income category in 2010. For all pollutants except $\mathrm{O}_{3}$, national mean exposures were higher for lower-income than for higher-income households (Fig. 3). Comparing national mean exposures for lowest-income $(<\$ 10,000 ; 7.2 \%$ of the households with income data) versus for highest-income ( $\$ 200,000 ; 4.2 \%$ ) households, exposures for lowest income households were $16 \%$ (relative to national mean exposure) higher for $\mathrm{SO}_{2}, 6.6 \%$ higher for $\mathrm{PM}_{2.5}$, and 5.2\% higher for $\mathrm{PM}_{10}$. For $\mathrm{NO}_{2}, \mathrm{CO}$, and $\mathrm{O}_{3}$, exposures for lowest- and highest-income households were similar $(\sim \pm 2 \%)$. Based on differences in average exposures between the approximate $25^{\text {th }}$ and $75^{\text {th }}$ percentiles for income $(\$ 20,000-25,000$ [midpoint: \$22,500], $\$ 75,000-100,000$ [midpoint: $\$ 87,500]$ ]), a $\$ 10,000$ increase in income was associated with an average reduction in concentration (expressed as a percent of the national mean concentration) of $0.90 \%$ for $\mathrm{SO}_{2}, 0.41 \%$ for $\mathrm{PM}_{2.5}, 0.36 \%$ for $\mathrm{NO}_{2}$, and $0.22 \%$ for $\mathrm{PM}_{10}$ and $\mathrm{CO}$, and an increase of $0.16 \%$ for $\mathrm{O}_{3}$.

\section{By Both Race-Ethnicity and Income}

In this section, we present exposure disparities accounting for both race-ethnicity and income together for census householders (hereafter, "households"). For all six pollutants, the absolute exposure disparity between the most- and least-exposed racial-ethnic groups was larger (on average, $\sim 6 \times$ larger; $1.1 \times$ for $\mathrm{SO}_{2}, 21 \times$ for $\mathrm{NO}_{2}, 1.4 \times-6.8 \times$ for the remaining pollutants) than the absolute exposure disparity between the lowest- and highest-income categories in 2010 (relative disparity: on average, $\sim 1.2 \times$ larger). For all income levels and pollutants, the mostexposed racial-ethnic group was a racial-ethnic minority group (Fig. 3). For five of the six pollutants (not $\mathrm{SO}_{2} ; \mathbf{F i g . ~ 3}$ ), average exposures were higher on average for Black households at the approximate $75^{\text {th }}$ percentile for income (income category midpoint: $\$ 87,500$ ) than for nonHispanic White households at the approximate $25^{\text {th }}$ percentile for income (midpoint: $\$ 22,500$ ). Racial-ethnic exposure disparities tended to be comparatively smaller at higher incomes than at lower incomes (except for $\mathrm{O}_{3}$ ), but the size of that effect was modest. For example, the absolute exposure disparity between the most- and least-exposed racial-ethnic groups (Fig. 3) was, on average, $9.5 \%$ lower for households at the approximate $75^{\text {th }}$ percentile than at the approximate $25^{\text {th }}$ percentile of income.

Income distributions varied by racial-ethnic group. For example, non-Hispanic White households represented $61 \%$ of the lowest income category $(<\$ 10,000)$ and $85 \%$ of the highest income category ( $>200,000$ ), versus $23 \%$ and $3.5 \%$, respectively, for non-Hispanic Black households, $13 \%$ and $4.3 \%$ for Hispanic households, and 3.5\% and 6.9\% for non-Hispanic Asian households. To quantify racial-ethnic exposure disparities after accounting for racial-ethnic income distribution variation, we calculated the absolute exposure disparity between the mostand least- exposed racial-ethnic groups within each income category in 2010 and then averaged across all 16 income categories. The resulting national absolute exposure disparity between most- and least-exposed racial-ethnic groups averaged across income categories and normalized to national mean exposure (i.e., expressed as a percent of the national mean concentration) was $58 \%$ for $\mathrm{NO}_{2}, 4.5 \%$ for $\mathrm{O}_{3}, 12 \%$ to $17 \%$ for the remaining pollutants. Conversely, to quantify income exposure disparities after accounting for race-ethnicity, we calculated the absolute 
income disparity within each racial-ethnic group and averaged across the four racial-ethnic groups. The resulting national absolute exposure disparity between lowest and highest income categories normalized to national mean exposure was $15 \%$ for $\mathrm{SO}_{2},-2.9 \%$ for $\mathrm{O}_{3}$, and $2.7 \%$ to $6.3 \%$ for the remaining pollutants.

We also conducted two counterfactual analyses to explore the interactions between raceethnicity and income in explaining national exposure disparities. Both counterfactuals slightly shifted the calculated exposure disparities, but support the conclusion that racial-ethnic exposure disparities were distinct from, and larger than, exposure disparities by income. The first counterfactual (holding income constant for racial-ethnic groups) shifted the absolute disparity between most- and least-exposed racial-ethnic group normalized to pollutant's national mean exposure by 0.03 percentage units on average (average of absolute values: 1.0 percentage units; range among pollutants: -1.9 to +2.4 percentage units). The second counterfactual (holding raceethnicity constant for income categories) shifted the absolute disparity between highest and lowest income categories normalized to pollutant's national mean exposure by -2.2 percentage units (average of absolute values: 2.2 percentage units; range among pollutants: -7.1 to -0.03 percentage units). In conclusion, exposure disparities by race-ethnicity did not substantially shift after accounting for income differences.

\section{Racial-ethnic Exposure Disparities by State and by Urbanicity in 2010}

\section{By State}

We explored how exposures varied by state, pollutant, and racial-ethnic group in 2010 (Fig. 4). The analysis separately considers the District of Columbia (DC) plus the 48 states of the contiguous US (hereafter, "states" refers to 48 states and DC, a total of 49 geographic units in state-level related calculations). There are 294 pollutant-state combinations (6 pollutants $\times 49$ units and 1176 pollutant-state-groups ( 294 pollutant-states $\times 4$ racial-ethnic groups). For this section, we define $\pm 5 \%$ (all percentages used in this section were expressed as a percent of the national mean exposure in 2010) as "similar to", and therefore report examples where exposures differ from the average by $>5 \%$ (or, in a sensitivity test, $>20 \%$ ). For example, " $>5 \%$ lower-thanaverage" means the exposure is lower-than-average by an amount greater than 5\%.

Overall, several spatial patterns emerge across states. First, racial-ethnic exposure disparities were ubiquitous among US states. In all 48 states and DC, one or more racial-ethnic groups experienced exposures $>5 \%$ of the area average exposure in 2010. Second, racial-ethnic minority populations within states were much more likely to have been more-exposed versus less-exposed than average; in contrast, non-Hispanic White populations within states experienced exposures $>5 \%$ above average in no states. Third, having exposures $>5 \%$ lowerthan-average within a state was much more likely to happen for non-Hispanic White populations than for racial-ethnic minority populations (Fig. 4, right column). Fourth, racial-ethnic exposure disparities were, on average, largest for $\mathrm{NO}_{2}$ and smallest for $\mathrm{O}_{3}$ among states.

Those findings reflect underlying trends across states, pollutants, and racial-ethnic groups. For example, for the non-Hispanic White group, $87 \%$ of the 294 pollutant-states had exposures that were similar $( \pm 5 \%)$ to the average, $13 \%$ had exposures $>5 \%$ less than average, and none were $>5 \%$ greater than average. In contrast, for exposures for the three racial-ethnic minority groups, $42 \%$ (of 882 pollutant-state-groups) were $>5 \%$ greater than average, $55 \%$ were $\pm 5 \%$ of the average, and only $4 \%$ were $>5 \%$ less than average. Thus, within individual states, the non-Hispanic White group was exposed to pollution levels that were similar to or cleaner than 
average, whereas the three racial-ethnic minority groups were more likely to be exposed to dirtier rather than cleaner pollution levels. For example, averaged across pollutants, the proportion of the states for which exposures were $>5 \%$ greater than average is $73 \%$ for nonHispanic Black populations, 57\% for Hispanic populations, 35\% for non-Hispanic Asian populations, and zero for non-Hispanic White populations.

The three racial-ethnic minority groups were disproportionately likely to be the mostexposed group, and disproportionately unlikely to be the least-exposed group of the four racialethnic groups across states. For example, the most-exposed group (for all cases, not just cases $>5 \%$ greater than average) was the non-Hispanic Black group for $45 \%$ of the 294 pollutantareas, the Hispanic group for $29 \%$, the non-Hispanic Asian group for $18 \%$, and non-Hispanic White group for $7.5 \%$. In contrast, the least-exposed group was rarely a racial-ethnic minority group ( $\sim 8 \%$ of all 294 pollutant-states for the non-Hispanic Black and for Hispanic group, $15 \%$ for the non-Hispanic Asian group) and was usually (70\% of 294 pollutant-states) the nonHispanic White group.

As a sensitivity test, we changed the analysis threshold to exposures $>20 \%$ greater than average (rather than 5\%). Here, we again found that the air pollution disproportionately impacted racial-ethnic minority groups. For example, exposure disparities $>20 \%$ of national mean exposure for one or more pollutant-groups occurred for 67\% of states (Fig. 4, left four columns for six pollutants), further emphasizing that disparities were widespread across states in 2010.

Fig. 4 reveals differences among states. For example, the four most populous states (California, Florida, New York, Texas), all have large, racially/ethnically diverse urban areas. However, average disparities between racial-ethnic minority populations and non-Hispanic White populations (Fig. 4 bottom right) were notably larger (on average, $6 \times$ larger) for California and New York than for Florida and Texas. Some small, relatively rural states also had substantial exposure disparities. Examples include $\mathrm{NO}_{2}$ in Nebraska (19\%) and $\mathrm{PM}_{2.5}$ in Nebraska (8.1\%).

\section{By Urbanicity}

We investigated racial-ethnic and income-based exposure disparities in 2010 separately for block groups that were defined as urban ( $89 \%$ of the population) versus rural (11\% of the population).

The racial-ethnic exposure disparities were generally larger for urban than for rural block groups. Specifically, the average exposure disparity between the most- and least-exposed racialethnic group was $5.5 \times$ larger for absolute disparity $(1.2 \times$ for relative disparity [ratio] $)$ for urban block groups than for rural block groups for $\mathrm{NO}_{2}, 3.1 \times(1.0 \times)$ larger for $\mathrm{O}_{3}, 2.4 \times(1.1 \times)$ larger for $\mathrm{CO}, 1.8 \times(1.0 \times)$ larger for $\mathrm{SO}_{2}$, and $1.2 \times(1.0 \times)$ larger for $\mathrm{PM}_{10}$. In contrast, for $\mathrm{PM}_{2.5}$, the average racial-ethnic exposure disparity was $1.2 \times(1.0 \times)$ larger for rural block groups than for urban block groups.

The most- and least-exposed of the four racial-ethnic groups differed between urban and rural areas for $\mathrm{SO}_{2}$ and for $\mathrm{O}_{3}$. For $\mathrm{SO}_{2}$, the most-exposed racial-ethnic group was the nonHispanic Black group in urban areas and the non-Hispanic White group in rural areas. For $\mathrm{O}_{3}$, the most-exposed racial-ethnic group was the non-Hispanic Asian group in urban areas and nonHispanic White group in rural areas. For the remaining four pollutants, the most-exposed group was a racial-ethnic minority group in both urban and rural areas.

Exposure disparities by income category were also larger in urban than in rural areas. Absolute exposure disparities between lowest and highest income category were $1.1 \times\left[\mathrm{PM}_{2.5}\right]$ to 
$25 \times\left[\mathrm{O}_{3}\right]$ (median: $3.5 \times$ ) greater (for relative disparity [ratio], range: $0.98 \times$ to $1.1 \times$, median: $1.0 \times$ ) in urban than in rural areas. Of the 12 pollutant-urbanicity categories ( 6 pollutants $\times 2$ urbanicities), exposures were higher for the lowest-income category than for the highest-income category in all cases except for $\mathrm{O}_{3}$ in urban areas and for $\mathrm{NO}_{2}$ in rural areas.

\section{Changes in National Exposures and Exposure Disparities from 1990 - 2010}

Criteria air pollution levels have declined in the US in the decades following the 1990 Clean Air Act amendments (US EPA 2020). To investigate if these reductions have led to reductions in racial-ethnic exposure disparities, we compared average exposures by racial-ethnic group from 1990 to 2010, for five of the pollutants. Exposure model results for $\mathrm{PM}_{2.5}$ were only available from 2000 to 2010, so those results are presented separately.

National mean pollution levels of all six pollutants fell over the study period. For example, from 1990 to 2010, the national mean exposures decreased for all five pollutants by an average of $40 \%$ relative to national mean exposures in 1990 (range: $-6 \%\left[\mathrm{O}_{3}\right]$ to $-71 \%\left[\mathrm{SO}_{2}\right]$; $34 \%$ to $-55 \%$ for remaining three pollutants). $\mathrm{PM}_{2.5}$ exposures decreased $29 \%$ from 2000 to 2010.

The average exposure disparities also declined from $1990-2010$. The amount of change depends in part on whether one considers absolute or relative disparities. In terms of absolute disparities, the disparities between the most- and least-exposed racial-ethnic groups decreased on average by $69 \%$ relative to absolute disparity in 1990 across the five pollutants. The largest change was an $88 \%$ decrease for CO disparities $(0.40 \mathrm{ppm}$ in 1990, $0.044 \mathrm{ppm}$ in 2010, a 0.35 ppm [i.e., 88\%] change) and the smallest change was a 54\% decrease for $\mathrm{NO}_{2}(9.8 \mathrm{ppb}$ [1990], $4.6 \mathrm{ppb}$ [2010], a $5.3 \mathrm{ppb}$ [54\%] change). From 2000 to 2010, $\mathrm{PM}_{2.5}$ disparities decreased by $35 \%$ (1.9 $\mathrm{g} \mathrm{m}^{-3}$ [2000], $1.2 \mu \mathrm{g} \mathrm{m}^{-3}$ [2010], a $0.66 \mu \mathrm{g} \mathrm{m}^{-3}$ change).

In terms of relative disparities, the greatest change was a decrease for $\mathrm{CO}$ (disparities: 1.63 [1990], 1.15 [2010]) and the smallest was a decrease for $\mathrm{O}_{3}$ (1.10 [1990], 1.04 [2010]); remaining pollutants were between $0.070-0.074$ decrease in relative disparity. $\mathrm{PM}_{2.5}$ relative disparity remained constant ( 1.1) from 2000 to 2010.

Shifting the comparison to the proportion of each racial-ethnic group in a location (unit of analysis: census block group) yields similar conclusions for changes in disparities during 1990 to 2010. For example, absolute air pollution level disparities between census block group bins with the highest versus lowest deciles of proportions of racial-ethnic minority residents $\left(90^{\text {th }}-100^{\text {th }}\right.$ versus $1^{\text {st }}-10^{\text {th }}$ percentiles in Fig. 2) decreased for four pollutants, on average by $60 \%$ relative to absolute disparity between the highest versus lowest deciles bins in $1990\left(\mathrm{CO}, \mathrm{NO}_{2}, \mathrm{PM}_{10}, \mathrm{SO}_{2}\right)$. For $\mathrm{O}_{3}$, disparities decreased slightly, from near-zero in 1990 to $0.46 \mathrm{ppb}$ (which is $1.0 \%$ of the national mean exposure) in 2010. $\mathrm{PM}_{2.5}$ disparities decreased 58\% from 2000 to 2010.

In addition to national changes, we investigated changes in absolute racial-ethnic exposure disparities from 1990 to 2010 by state and by urban versus rural areas. Most states (>75\%) experienced a reduction in racial-ethnic exposure disparities for pollutants except for $\mathrm{PM}_{10}$ (and, except for $\mathrm{PM}_{2.5}$ during 2000-2010). Urban areas experienced larger reductions in racial-ethnic exposure disparities than did rural areas for $\mathrm{NO}_{2}$ and $\mathrm{PM}_{10}(13 \times$ larger reductions in urban areas, for both pollutants), $\mathrm{CO}(2.4 \times)$, and $\mathrm{SO}_{2}(1.2 \times)$. Conversely, $\mathrm{PM}_{2.5}$ (during 20002010) and $\mathrm{O}_{3}$ (during 1990-2010) had larger reductions in absolute racial-ethnic disparities for rural than for urban $(2.4 \times$ and $3.4 \times$ larger in rural areas, respectively).

Finally, we investigated whether the changes in absolute racial-ethnic exposure disparities from 1990 to 2010 were more attributable to changes in air pollution levels or to 
changes in demographic patterns (migration, immigration, and other factors). Based on a counterfactual analysis, reductions in racial-ethnic exposure disparities between the most- and least- exposed racial-ethnic groups were mainly attributable to changes in air pollution levels rather than to changes in demographic patterns. On average across all pollutants, $87 \%$ of the reduction in the absolute racial-ethnic disparity metric was attributable to changes in air pollution levels from 1990 to 2000 (excluding PM$_{2.5}$ based on lack of available data), and 97\% from 2000 to 2010 (Table S37).

\section{Discussion}

Our research provides the first national investigation of air pollution exposure disparities by income and race-ethnicity for all criteria pollutants (except lead). Our results reveal trends by pollutant and across time and space.

In 2010, on average nationally, racial-ethnic minority populations were exposed to higher average levels of transportation-related air pollution $\left(\mathrm{CO}, \mathrm{NO}_{2}\right)$ and particulate matter $\left(\mathrm{PM}_{2.5}\right.$, $\mathrm{PM}_{10}$ ) than non-Hispanic White populations. This finding, which holds even after accounting for uncertainties in the predictions from exposure models, is consistent with prior national studies of $\mathrm{NO}_{2}, \mathrm{PM}_{2.5}$, and $\mathrm{PM}_{10}$ (Clark et al. 2017; Kravitz-Wirtz et al. 2016; Mikati et al. 2018; Tessum et al. 2019; Colmer et al. 2020). Disparities for the remaining pollutants $\left(\mathrm{CO}, \mathrm{O}_{3}\right.$ and $\left.\mathrm{SO}_{2}\right)$ had not been previously studied in detail for the national population, and few studies have considered how disparities for any pollutant have changed across 20 years (Kravitz-Wirtz et al. 2016; Bullard et al. 2008).

Our findings on "which group was most-exposed?" (on average, nationally) varied by pollutant, but in all six cases the most exposed group was a racial-ethnic minority group. That result is consistent with prior national studies, which have reported, for example, highest average $\mathrm{NO}_{2}$ exposures for Hispanic Black and non-Hispanic Asian populations (Clark et al. 2017), and highest average proximities to industrial $\mathrm{PM}_{2.5}$ emissions (Mikati et al. 2018) and highest average exposures to industrial air toxins (Ard 2015) for non-Hispanic Black populations.

We found that racial-ethnic minority populations were more than two times as likely than non-Hispanic white populations to live in a census block group with highest air pollution levels (above $90^{\text {th }}$ percentile) on average. Those results are consistent with existing literature on disproportionate environmental risks for racial-ethnic minority populations (Collins 2016) and on groups or locations with higher risks for one environmental factor having higher risks for other factors too (Morello-Frosch and Lopez 2006; Su et al. 2012).

We found that air pollution exposures were generally higher for lower-income households (for all pollutants except $\mathrm{O}_{3}$ ). This finding is consistent with previous national research (e.g., for industrial $\mathrm{PM}_{2.5}$ emissions (Mikati et al. 2018), industrial air toxins (Ard 2015), and $\mathrm{PM}_{2.5}$ and $\mathrm{NO}_{2}$ (Clark et al. 2014; Kravitz-Wirtz et al. 2016)). Additionally, we found that, in 2010, absolute racial-ethnic exposure disparities were distinct from, and were larger than (on average, $\sim 6 \times$ larger than), absolute exposure disparities by income. The findings are inconsistent with the idea that racial-ethnic exposure disparities can be explained by, or are "merely" a reflection of, income disparities among racial-ethnic groups.

The findings from this study can be used to compare relative exposure disparities for different criteria air pollutants in a consistent way, providing additional context for previous studies of single pollutants. We found that in 2010, relative racial-ethnic exposure disparities (i.e., ratios of average exposures between the most- and least-exposed groups) were largest for $\mathrm{NO}_{2}$ and smallest for $\mathrm{O}_{3}$. Relative income-based exposure disparities (i.e., ratios of average 
exposures between the lowest and highest income groups), although smaller than racial-ethnic exposure disparities for each pollutant, were largest for $\mathrm{SO}_{2}$ and smallest (and similar) for $\mathrm{NO}_{2}$, $\mathrm{CO}$, and $\mathrm{O}_{3}$. (These results provide information on the rank-order of relative disparities in air health impacts by pollutant would require further analysis, as discussed next).

Exposure disparities often connect with health disparities. Based on the magnitude of exposure disparities (e.g., 2010 national average $\mathrm{PM}_{2.5}$ exposures for non-Hispanic Black people were $1.0 \mu \mathrm{g} \mathrm{m}^{-3}$ higher-than-average), the resulting health disparities may be substantial (thousands of additional premature mortalities per year). Future research could usefully extend our exposure disparity results to provide rigorous, comprehensive investigation of the associated health impacts.

State-level results may be especially useful given the important role that states play in air pollution and environmental policy making (Abel et al. 2015). Exposures $>5 \%$ greater than the national mean exposure within states were common for racial-ethnic minority populations, but not for non-Hispanic white populations. Exposure disparities varied substantially among states, even among states with similar characteristics (e.g., urbanicity, population, region). Our results emphasize differences among states in the level and makeup of exposure disparities, yet also demonstrate that exposure disparities were ubiquitous, including both large and small states, and states in all regions of the US, in 2010.

Our analyses by urbanicity were in part motivated by, and reflect, urban-rural differences in demographics and air pollution levels (Clark et al. 2017; Mikati et al. 2018; Rosofsky et al. 2018). Racial-ethnic disparities were larger for urban block groups for all pollutants except $\mathrm{PM}_{2.5}$. Of the six pollutants, the largest ratio between urban and rural racial-ethnic absolute disparity (5.5x larger) was for $\mathrm{NO}_{2}$. The $\mathrm{NO}_{2}$ results are consistent with prior research (Clark et al. 2017). Over our study period, reductions in absolute racial-ethnic exposure disparity for $\mathrm{PM}_{2.5}$ and $\mathrm{O}_{3}$ were larger for rural than for urban areas, likely reflecting the fact that $\mathrm{O}_{3}$ and most of $\mathrm{PM}_{2.5}$ are secondary pollutants versus the other pollutants being mainly primary pollutants. Controlling for urbanicity, exposures were mostly higher for the lowest income category than the highest. Absolute income-based exposure disparities were also 7.5 times larger on average in urban than in rural areas.

The results by state and by urbanicity reflect that exposure disparities differ by spatial units (e.g., urban/rural, and by state); future research could explore these aspects further, for example, through a spatial decomposition of national exposure disparities.

Regulations such as the 1990 Clean Air Act Amendments have achieved substantial reductions in the concentrations of many pollutants. Our analysis reveals that, as a co-benefit, falling pollution levels have reduced absolute exposure disparities among racial-ethnic groups. These findings are consistent with previous national research for $\mathrm{NO}_{2}, \mathrm{PM}_{2.5}$, and industrial air toxins (Ard 2015; Clark et al. 2017; Kravitz-Wirtz et al. 2016; Colmer et al. 2020). We found that a larger share of the racial-ethnic exposure disparity reduction was attributable to air pollution level reduction rather than changes in demographic and residential patterns.

Our study described patterns in exposure disparities but did not investigate aspects such as underlying causes or ethical or legal aspects. Systemic racism and racial segregation are two major causes discussed in multiple previous studies (Jones et al. 2014; Morello-Frosch and Lopez 2006; Schell et al. 2020). Future longitudinal research could further investigate the underlying causes of exposure disparities. One important dimension not considered here is responsibility for generating pollution. Recent analysis suggests that Hispanic and Black 
populations have disproportionately lower consumption of goods and services whose emissions lead to $\mathrm{PM}_{2.5}$ air pollution (Tessum et al. 2019).

Our study has several limitations. The finest spatial scale of publicly-available Census

demographic data for race-ethnicity and income is at Census block group level; we were unable to assess disparities at finer spatial scales than what the Census provides. Our disparity estimates do not account for (1) daily mobility for work, shopping, recreation, and other activities, (2) direct indoor exposure to indoor sources such as cigarette smoke, cooking emissions, or incense, (3) indoor-outdoor relationships in pollution levels, such as particle losses during airflow in ducts or ozone losses to indoor surfaces, or (4) occupational exposures. Our exposure disparity estimates were limited by uncertainties in the CACES exposure model predictions and in Census demographic data. Our uncertainty analysis (but not our main analysis) was limited to US EPA monitoring locations; we were not able to test potential exposure errors at locations without monitors on the national scale.

Our study provides the first national analysis of air pollution exposure disparities among income and racial-ethnic groups, for all criteria pollutants (except lead), including trends across time (by decade, 1990-2010) and spatial location (by state and for urban versus rural areas). On average, exposures were generally higher for racial-ethnic minority populations than for nonHispanic White populations. Exposures were also, on average, higher for the lowest-income households than for the highest-income households. However, exposure disparities by raceethnicity were not explained by disparities in income. Racial-ethnic exposure disparities declined from 1990 to 2010 (on an absolute basis), but still existed in all states in 2010. Among pollutants, national racial-ethnic exposure disparities were largest for $\mathrm{NO}_{2}$ and smallest for $\mathrm{O}_{3}$.

\section{Reference}

1. Abel TD, Salazar DJ, Robert P. 2015. States of environmental justice: redistributive politics across the United States, 1993-2004. Rev Policy Res 32(2):200-225, doi:10.1111/ropr.12119.

2. Ard K. 2015. Trends in exposure to industrial air toxins for different racial and socioeconomic groups: A spatial and temporal examination of environmental inequality in the U.S. from 1995 to 2004. Soc Sci Res 53: 375-390; PMID:26188461, doi:http://dx.doi.org/10.1016/j.ssresearch.2015.06.019.

3. Bowe B, Xie Y, Yan Y, Al-Aly Z. 2019. Burden of cause-specific mortality associated with $\mathrm{PM}_{2.5}$ air pollution in the United States. JAMA Netw open 2(11):e1915834; PMID:31747037, doi:10.1001/jamanetworkopen.2019.15834.

4. Brulle RJ, Pellow DN. 2006. Environmental justice: human health and environmental inequalities. Annu Rev Public Health 27(1):103-124; PMID:16533111, doi:10.1146/annurev.publhealth.27.021405.102124.

5. Bullard RD, Mohai P, Saha R, Wright B. 2008. Toxic wastes and race at twenty: Why race still matters after all of these years. Envtl L. 38(2):371-411; doi:http://www.jstor.org/stable/43267204.

6. Bullock C, Ard K, Saalman G. 2018. Measuring the relationship between state environmental justice action and air pollution inequality, 1990-2009. Rev Policy Res 35(3):466-490; doi:10.1111/ropr.12292.

7. Clark LP, Millet DB, Marshall JD. 2014. National patterns in environmental injustice and inequality: Outdoor $\mathrm{NO}_{2}$ air pollution in the United States. PLoS One 9(4):e94431; PMID:24736569, doi:10.1371/journal.pone.0094431. 
8. Clark LP, Millet DB, Marshall JD. 2017. Changes in transportation-related air pollution exposures by race-ethnicity and socioeconomic status: Outdoor nitrogen dioxide in the United States in 2000 and 2010. Environ Health Perspect 125(9):1-10; PMID: 28930515, doi:10.1289/EHP959.

9. Cohen AJ, Brauer M, Burnett R, Anderson HR, Frostad J, Estep K, et al. 2017. Estimates and 25-year trends of the global burden of disease attributable to ambient air pollution: an analysis of data from the Global Burden of Diseases Study 2015. Lancet 389:1907-1918; PMID:28408086, doi: http://dx.doi.org/10.1016/S0140-6736(17)30505-6.

10. Collins MB, Munoz I, Jaja J. 2016. Linking “toxic outliers” to environmental justice communities. Environ Res Lett 11; doi:10.1088/1748-9326/11/1/015004.

11. Colmer J, Hardman I, Shimshack J, Voorheis J. 2020. Disparitie in $\mathrm{PM}_{2.5}$ air pollution in the United States. Science 369(6503): 575-578; PMID:32732425, doi:10.1126/science.aaz9353.

12. Darrow LA, Klein M, Strickland MJ, Mulholland JA, Tolbert PE. 2011. Ambient air pollution and birth weight in full-term infants in Atlanta, 1994-2004. Environ Health Perspect 119(5):731-737; PMID:21156397, doi:10.1289/ehp.1002785.

13. Downey L, Dubois S, Hawkins B, Walker M. 2008. Environmental inequality in metropolitan America. Organization \& Environment 21(3):270-294; PMID:19960094, doi: $10.1177 / 1086026608321327$.

14. Evans GW, Kantrowitz E. 2002. Socioeconomic status and health: the potential role of environmental risk exposure. Annu Rev Public Health 23(1):303-331; PMID:11910065, doi:10.1146/annurev.publhealth.23.112001.112349.

15. Fann N, Coffman E, Hajat A, Kim SY. 2019. Change in fine particle-related premature deaths among US population subgroups between 1980 and 2010. Air Qual Atmos Heal 12:673-682; doi:http://doi.org/10.1007/s11869-019-00686-9.

16. Gee GC, Payne-Sturges DC. 2004. Environmental health disparities: A framework integrating psychosocial and environmental concepts. Environ Health Perspect 112:1645-1653; PMID:15579407, doi:10.1289/ehp.7074.

17. Hajat A, Hsia C, O’Neill MS. 2015. Socioeconomic disparities and air pollution exposure: a global review. Curr Environ Heal reports 2:440-450; PMID:26381684, doi:10.1007/s40572-015-0069-5.

18. Harper S, Ruder E, Roman HA, Geggel A, Nweke O, Payne-Sturges D, et al. 2013. Using inequality measures to incorporate environmental justice into regulatory analyses. Int $\mathbf{J}$ Environ Res Public Health 10:4039-4059; doi:10.3390/ijerph10094039.

19. Jones MR, Diez-Roux A V., Hajat A, Kershaw KN, O’Neill MS, Guallar E, et al. 2014. Race/ethnicity, residential segregation, and exposure to ambient air pollution: The MultiEthnic Study of Atherosclerosis (MESA). Am J Public Health 104:2130-2137; doi:10.2105/AJPH.2014.302135.

20. Kim SY, Bechle M, Hankey S, Sheppard L, Szpiro AA, Marshall JD. 2020. Concentrations of criteria pollutants in the contiguous U.S., 1979 - 2015: Role of prediction model parsimony in integrated empirical geographic regression. PLoS One 15(2):1979-2015; PMID:32069301, doi:10.1371/journal.pone.0228535.

21. Kravitz-Wirtz N, Crowder K, Hajat A, Sass V. 2016. The long-term dynamics of racial/ethnic inequality in neighborhood air pollution exposure, 1990-2009. Du Bois Rev 13(2):237-259; PMID:28989341, doi:10.1017/S1742058X16000205.

22. Lelieveld J, Evans JS, Fnais M, Giannadaki D, Pozzer A. 2015. The contribution of 
outdoor air pollution sources to premature mortality on a global scale. Nature 525:367371; PMID:26381985, doi:10.1038/nature15371.

23. Manson S, Schroeder J, Van Riper D, Ruggles S. 2019. IPUMS National Historical Geographic Information System: Version 14.0 [Database]. http://doi.org/10.18128/D050.V14.0 [accessed 24 May 2020].

24. Marshall JD, Swor KR, Nguyen NP. 2014. Prioritizing environmental justice and equality: Diesel emissions in Southern California. Environ Sci Technol 48:4063-4068; PMID: 24559220, doi:http://dx.doi.org/10.1021/es405167f.

25. Mikati I, Benson AF, Luben TJ, Sacks JD, Richmond-Bryant J. 2018. Disparities in distribution of particulate matter emission sources by race and poverty status. Am J Public Health 108(4):480-485; PMID:29470121, doi:10.2105/AJPH.2017.304297.

26. Mohai P, Pellow D, Roberts JT. 2009. Environmental justice. Annu Rev Environ Resour 34:405-430; doi:10.1146/annurev-environ-082508-094348.

27. Morello-Frosch R, Lopez R. 2006. The riskscape and the color line: Examining the role of segregation in environmental health disparities. Environ Res 102(2):181-196; PMID:16828737, doi:10.1016/j.envres.2006.05.007.

28. Paul KC, Haan M, Mayeda ER, Ritz BR. 2019. Ambient air pollution, noise, and late-life cognitive decline and dementia risk. Annu Rev Public Health 40:203-220; PMID:30935305, doi:http://doi.org/10.1146/annurev-publhealth-040218-044058.

29. Pope CA, Ezzati M, Dockery DW. 2009. Fine-particulate air pollution and life expectancy in the United States. N Engl J Med 360 (4):376-86; PMID:19164188, doi:10.1056/NEJMsa0805646.

30. Ratcliffe M, Burd C, Holder K, Fields A. 2016. Defining rural at the U.S. Census Bureau (U.S. Census Bureau). https://www2.census.gov/geo/pdfs/reference/ua/Defining_Rural.pdf [accessed 7 July 2020].

31. Rivas I, Basagaña X, Cirach M, López-Vicente M, Suades-González E, Garcia-Esteban $\mathrm{R}$, et al. 2019. Association between early life exposure to air pollution and working memory and attention. Environ Health Perspect 127(5):1-11; PMID:31070940, doi:10.1289/EHP3169.

32. Rosofsky A, Levy JI, Zanobetti A, Janulewicz P, Fabian MP. 2018. Temporal trends in air pollution exposure inequality in Massachusetts. Environ Res 161(2018):76-86; PMID:29101831, doi:10.1016/j.envres.2017.10.028.

33. Salazar DJ, Clauson S, Abel TD, Clauson A. 2019. Race, income, and environmental inequality in the U.S. states, 1990-2014. Soc Sci Q 100(3):592-603; doi:10.1111/ssqu.12608.

34. Schell CJ, Dyson K, Fuentes TL, Des Roches S, Harris NC, Miller DS, et al. 2020. The ecological and evolutionary consequences of systemic racism in urban environments. Science 369; doi:10.1126/SCIENCE.AAY4497.

35. Stieb DM, Chen L, Eshoul M, Judek S. 2012. Ambient air pollution, birth weight and preterm birth: a systematic review and meta-analysis. Environ Res 117(2012):100-111; PMID:22726801, doi:10.1016/j.envres.2012.05.007.

36. Stanaway JD, Afshin A, Gakidou E, Lim SS, Abate D, Abate KH, et al. 2018. Global, regional, and national comparative risk assessment of 84 behavioural, environmental and occupational, and metabolic risks or clusters of risks for 195 countries and territories, 1990-2017: A systematic analysis for the Global Burden of Disease Study 2017. Lancet 
392:1923-1994; PMID:30496105, doi:10.1016/S0140-6736(18)32225-6.

37. State of California, Assembly Bill No. 617. 2017. Nonvehicular air pollution: criteria air pollutants and toxic air contaminants. https://leginfo.legislature.ca.gov/faces/billNavClient.xhtml?bill_id=201720180AB617 [accessed 16 Sep 2020].

38. Su JG, Jerrett M, Morello-Frosch R, Jesdale BM, Kyle AD. 2012. Inequalities in cumulative environmental burdens among three urbanized counties in California. Environ Int 40: 79-87; PMID:22280931, doi:10.1016/j.envint.2011.11.003.

39. Underwood E. 2017. The polluted brain. Science 355(6323):342-345; doi:10.1126/science.355.6323.342.

40. United States Census Bureau. 2013. Census bureau geography. http://www2.census.gov/geo/pdfs/reference/GARM/Ch11GARM.pdf [accessed 7 July 2020].

41. US Environmental Protection Agency. 2020. Our nation's air: status and trends through 2019. https://gispub.epa.gov/air/trendsreport/2020/ [accessed 7 July 2020].

42. Tessum CW, Apte JS, Goodkind AL, Muller NZ, Mullins KA, Paolella DA, et al. 2019. Inequity in consumption of goods and services adds to racial-ethnic disparities in air pollution exposure. Proc Natl Acad Sci U S A 116(13):6001-6006; PMID:30858319, doi:10.1073/pnas.1818859116.

43. The New School Tishman Environment and Design Center. 2019. "Local Policies for Environmental Justice: A National Scan". https://www.nrdc.org/sites/default/files/localpolicies-environmental-justice-national-scan-tishman-201902.pdf [accessed 9 July 2020].

44. Zwickl K, Ash M, Boyce JK. 2014. Regional variation in environmental inequality: industrial air toxics exposure in U.S. cities. Ecological Economics 107:494-509; doi:10.1016/j.ecolecon.2014.09.013. 
912 Table 1. Population distribution and population-weighted exposure distribution for six

913 criteria pollutants for four main racial-ethnic groups in year 2010.

\begin{tabular}{|c|c|c|c|c|c|}
\hline Demographic & $\begin{array}{l}\text { Non-Hispanic } \\
\text { White }\end{array}$ & $\begin{array}{l}\text { Non-Hispanic } \\
\text { Black }\end{array}$ & Hispanic & $\begin{array}{c}\text { Non-Hispanic } \\
\text { Asian }\end{array}$ & $\begin{array}{c}\text { Entire } \\
\text { Population }\end{array}$ \\
\hline $\begin{array}{l}\text { Proportion of } \\
\text { population }\end{array}$ & $64 \%$ & $12 \%$ & $16 \%$ & $4.6 \%$ & $100 \%$ \\
\hline \multicolumn{6}{|l|}{$\mathrm{PM}_{2.5}\left(\mu \mathrm{g} \mathrm{m}^{-3}\right)$} \\
\hline $10^{\text {th }}$ percentile & 6.1 & 7.9 & 6.5 & 6.7 & 6.3 \\
\hline $25^{\text {th }}$ percentile & 7.7 & 9.2 & 7.7 & 8.2 & 7.9 \\
\hline $50^{\text {th }}$ percentile & 9.3 & 10 & 9.6 & 9.7 & 9.5 \\
\hline Mean (SD) & $9.1(2.2)$ & $10(1.8)$ & $9.4(2.2)$ & $9.4(1.9)$ & $9.3(2.2)$ \\
\hline $75^{\text {th }}$ percentile & 11 & 11 & 11 & 11 & 11 \\
\hline $90^{\text {th }}$ percentile & 12 & 13 & 12 & 12 & 12 \\
\hline \multicolumn{6}{|l|}{$\mathrm{NO}_{2}(\mathrm{ppb})$} \\
\hline $10^{\text {th }}$ percentile & 3.1 & 3.8 & 4.6 & 5.4 & 3.4 \\
\hline $25^{\text {th }}$ percentile & 4.3 & 5.8 & 6.6 & 7.5 & 4.9 \\
\hline $50^{\text {th }}$ percentile & 6.2 & 8.7 & 9.5 & 10 & 7.4 \\
\hline Mean (SD) & $7.2(4.1)$ & $9.7(5.3)$ & $11(6.1)$ & $12(5.9)$ & $8.7(5.1)$ \\
\hline $75^{\text {th }}$ percentile & 8.9 & 12 & 15 & 15 & 11 \\
\hline $90^{\text {th }}$ percentile & 12.5 & 18 & 21 & 21 & 16 \\
\hline \multicolumn{6}{|l|}{$\mathrm{O}_{3}(\mathrm{ppb})$} \\
\hline $10^{\text {th }}$ percentile & 38 & 39 & 33 & 39 & 38 \\
\hline $25^{\text {th }}$ percentile & 43 & 43 & 42 & 44 & 43 \\
\hline $50^{\text {th }}$ percentile & 47 & 47 & 46 & 47 & 47 \\
\hline Mean (SD) & $46(6.0)$ & $46(6.1)$ & $45(7.2)$ & $46(5.9)$ & $46(6.2)$ \\
\hline $75^{\text {th }}$ percentile & 50 & 50 & 49 & 50 & 50 \\
\hline $90^{\text {th }}$ percentile & 52 & 53 & 52 & 53 & 52 \\
\hline \multicolumn{6}{|l|}{$\mathrm{SO}_{2}(\mathrm{ppb})$} \\
\hline $10^{\text {th }}$ percentile & 0.91 & 1.0 & 0.83 & 0.79 & 0.95 \\
\hline $25^{\text {th }}$ percentile & 1.1 & 1.2 & 1.0 & 1.0 & 1.2 \\
\hline $50^{\text {th }}$ percentile & 1.5 & 1.6 & 1.3 & 1.2 & 1.5 \\
\hline Mean (SD) & $1.6(0.65)$ & $1.7(0.63)$ & $1.4(0.55)$ & $1.4(0.58)$ & $1.6(0.64)$ \\
\hline $75^{\text {th }}$ percentile & 1.9 & 2.1 & 1.7 & 1.7 & 2.0 \\
\hline $90^{\text {th }}$ percentile & 2.4 & 2.5 & 2.2 & 2.3 & 2.5 \\
\hline \multicolumn{6}{|l|}{$\mathrm{PM}_{10}\left(\mu \mathrm{g} \mathrm{m}^{-3}\right)$} \\
\hline $10^{\text {th }}$ percentile & 12 & 14 & 15 & 14 & 13 \\
\hline $25^{\text {th }}$ percentile & 14 & 16 & 17 & 16 & 15 \\
\hline $50^{\text {th }}$ percentile & 17 & 19 & 20 & 19 & 18 \\
\hline Mean (SD) & $18(4.4)$ & $19(3.7)$ & $21(4.9)$ & $20(4.5)$ & $18(4.6)$ \\
\hline $75^{\text {th }}$ percentile & 21 & 21 & 23 & 22 & 22 \\
\hline $90^{\text {th }}$ percentile & 23 & 23 & 28 & 25 & 24 \\
\hline \multicolumn{6}{|l|}{ CO (ppm) } \\
\hline $10^{\text {th }}$ percentile & 0.23 & 0.25 & 0.26 & 0.27 & 0.24 \\
\hline
\end{tabular}




\begin{tabular}{|c|c|c|c|c|c|}
\hline $25^{\text {th }}$ percentile & 0.27 & 0.29 & 0.30 & 0.30 & 0.28 \\
\hline $50^{\text {th }}$ percentile & 0.31 & 0.32 & 0.34 & 0.34 & 0.31 \\
\hline Mean (SD) & & & & & 0.31 \\
& $0.30(0.057)$ & $0.32(0.067)$ & $0.35(0.079)$ & $0.35(0.071)$ & $(0.066)$ \\
\hline $75^{\text {th }}$ percentile & 0.33 & 0.35 & 0.39 & 0.38 & 0.35 \\
\hline $90^{\text {th }}$ percentile & 0.37 & 0.40 & 0.45 & 0.45 & 0.39 \\
\hline
\end{tabular}

914

915

916 
Figures
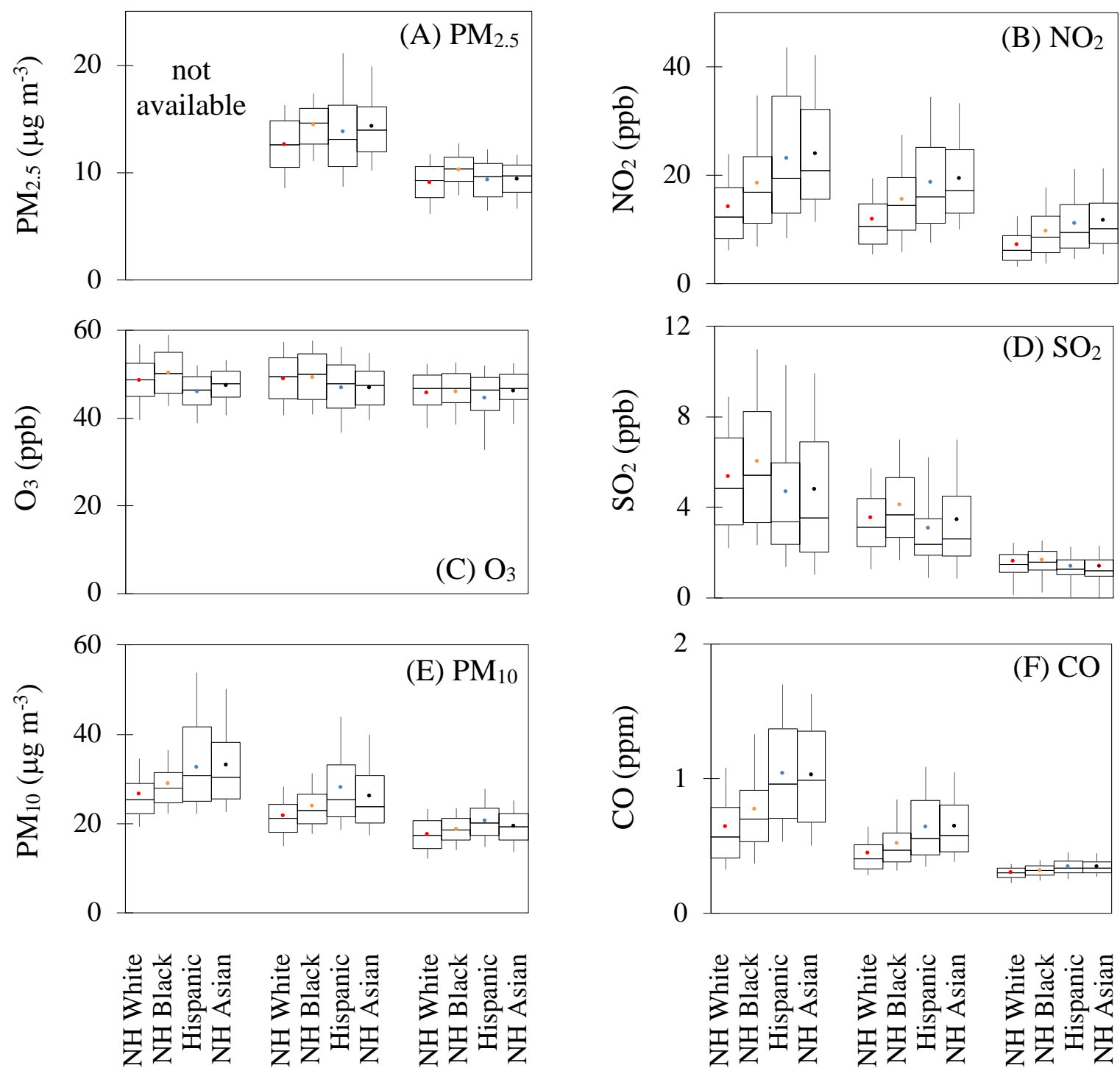

$$
2000 \quad 2010
$$

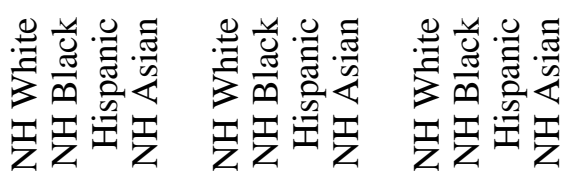

1990

2000

2010
918

919

920

921

922

923

924

925
Fig. 1. Distribution of exposure to pollutants in years 1990, 2000, and 2010, stratified by racial-ethnic group, for (A) $\mathrm{PM}_{2.5}$, (B) $\mathrm{NO}_{2}$, (C) $\mathrm{O}_{3}$, (D) $\mathrm{SO}_{2}$, (E) $\mathrm{PM}_{10}$, and (F) CO. For all panels, the highest/lowest bound represents the $90^{\text {th }} / 10^{\text {th }}$ percentile value, the box shows the $25^{\text {th }}$ and $75^{\text {th }}$ percentiles, and the horizontal line in the box represents the median. Color circles indicate the national population-weighted mean. $\mathrm{PM}_{2.5}$ has no estimates in 1990 because of a lack of monitoring data prior to 1999. "NH" refers to non-Hispanic. "Hispanic" refers to Hispanic people of any race(s). 

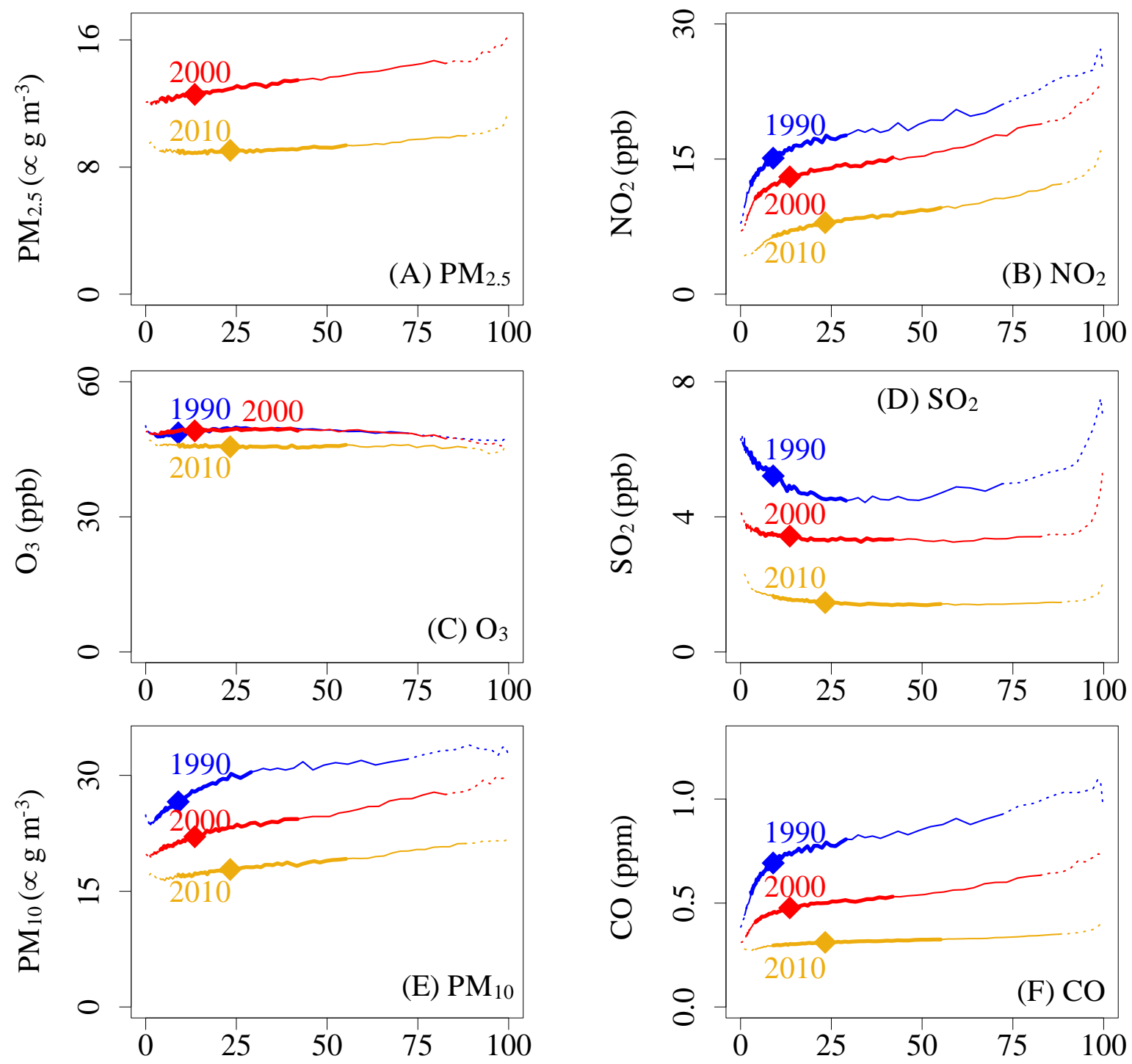

Racial-ethnic minority residents percentage $(\%)$

Racial-ethnic minority residents percentage $(\%)$

Fig. 2. Relationship between the proportion of racial-ethnic minority residents in census block groups and average criteria air pollution concentrations in the years 1990, 2000, and 2010 for A) PM2.5, (B) NO2, (C) O3, (D) SO2, (E) PM10, and (F) CO. For each panel, the bold portion of the line indicates the $25^{\text {th }}$ to $75^{\text {th }}$ percentile of census block groups, the thin line indicates the $10^{\text {th }}$ and $90^{\text {th }}$ percentiles, the dashed line indicates the $1^{\text {th }}$ and $99^{\text {th }}$ percentiles, and

932 the diamond icon indicates the median. 

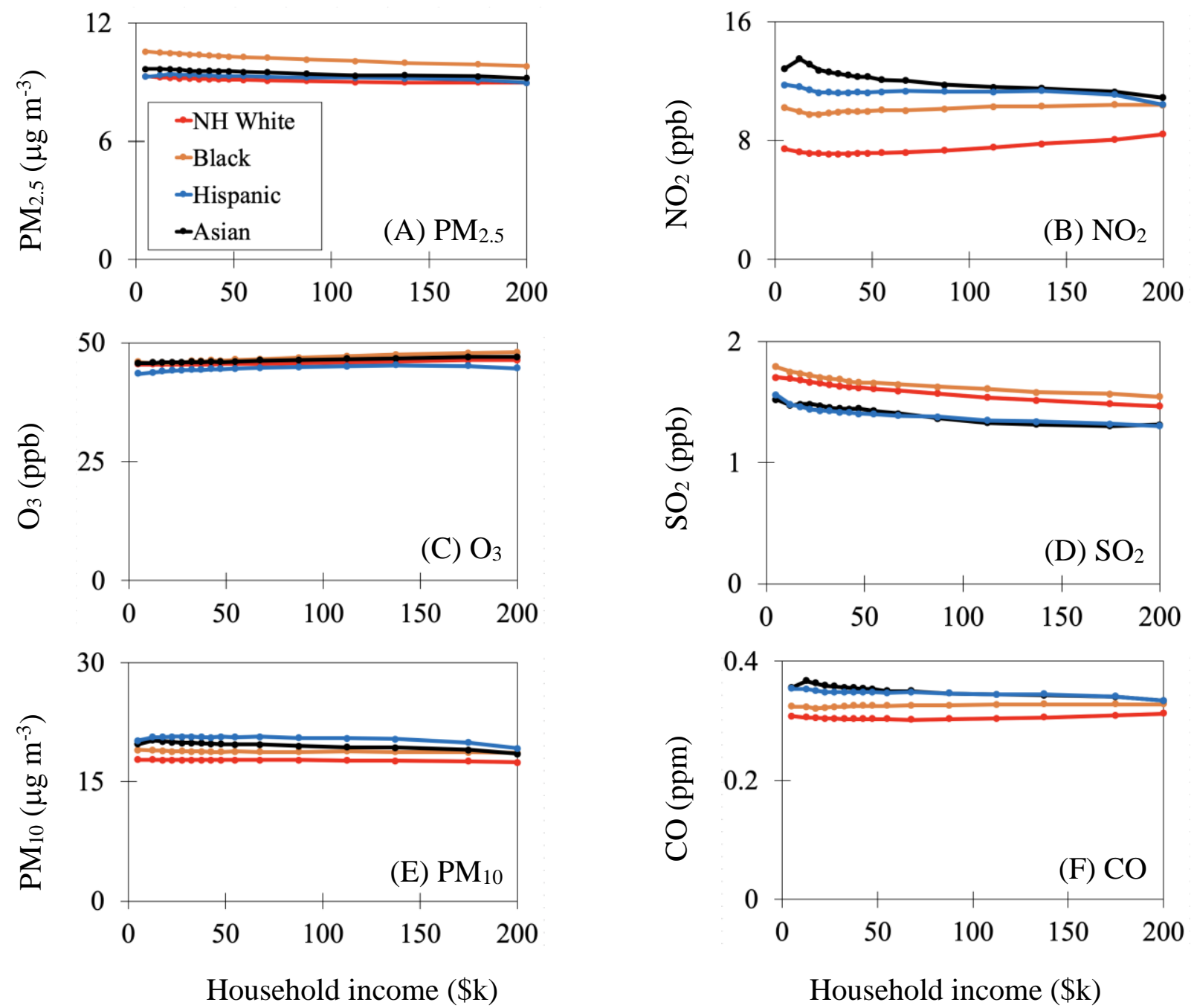

Fig. 3. Population-weighted criteria air pollution concentration in 2010 for 16 household income groups, stratified by race-ethnicity, for (A) $\mathrm{PM}_{2.5}$, (B) $\mathrm{NO}_{2}$, (C) $\mathrm{O}_{3}$, (D) $\mathrm{SO}_{2}$, (E) PM10, and (F) CO. For all panels, each data point represents pollution exposure for one income category and racial-ethnic group. "NH White" refers to non-Hispanic White people. "Hispanic" refers to Hispanic people of any race(s). "Asian" refers to Hispanic and non-Hispanic Asian people. "Black" refers to Hispanic and non-Hispanic Black people. Values plotted for household income are, for values below $\$ 200 \mathrm{k}$ (i.e., for the first 15 income categories), the midpoint value; 


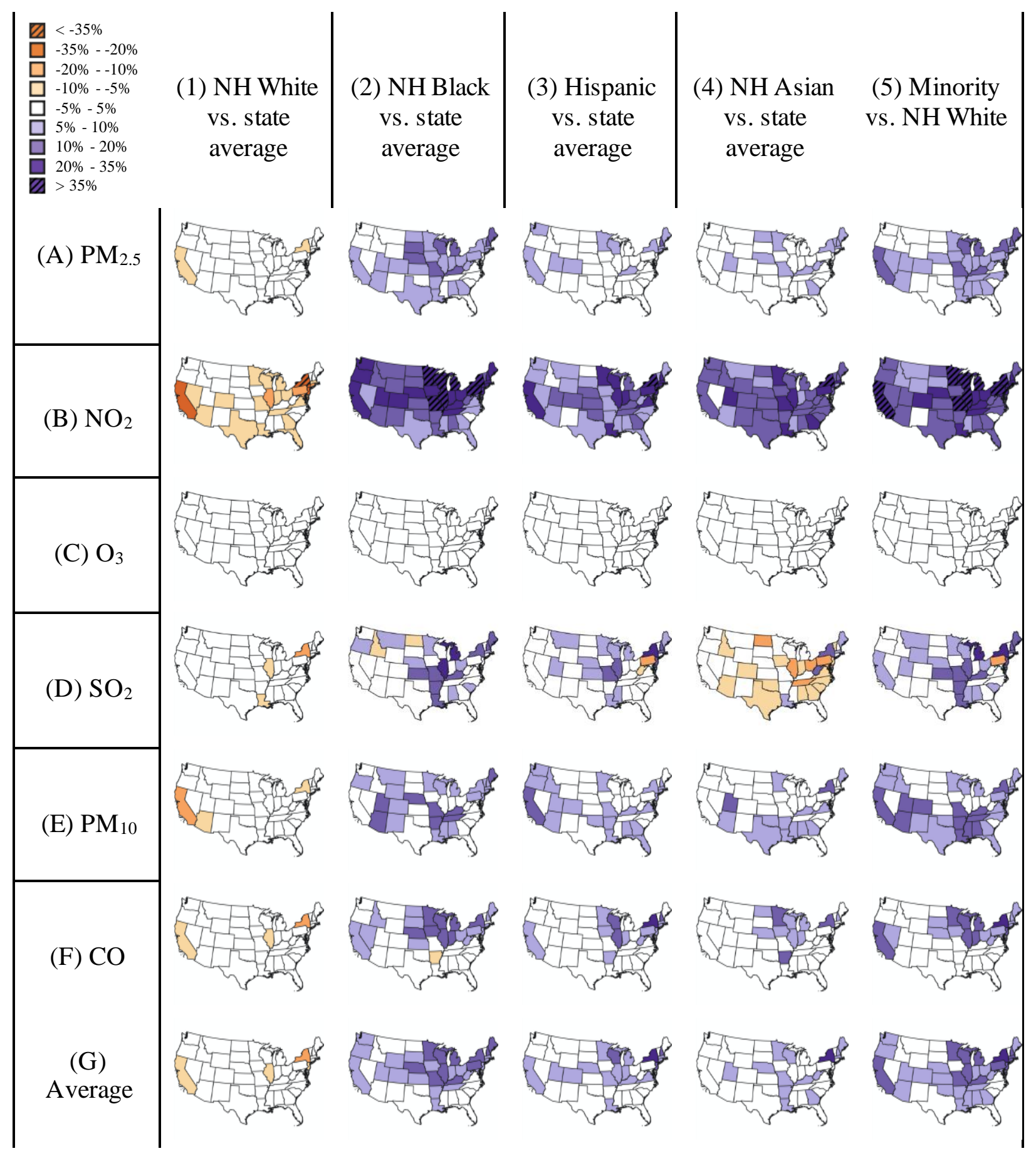

945

946

947

948

949
Fig. 4. State racial-ethnic disparities in average pollution exposure in 2010, showing the difference between (1) NH White vs. state average, (2) NH Black vs. state average, (3) Hispanic vs. state average, (4) NH Asian vs. state average, and (5) Minority vs. NH White for the six pollutants (A) PM2.5, (B) NO2, (C) O3, (D) $\mathrm{SO}_{2}$, (E) PM10, and (F) CO, and (G) 
average across the six pollutants. Columns 1-4: exposure disparity relative to state average; calculated as mean exposure for a racial-ethnic group in that state minus the overall mean for that state, then divided by the national overall mean. Column 5: exposure disparity for racial-ethnic minorities relative to the racial-ethnic majority group; calculated as mean exposure for racialethnic minorities minus mean exposure for non-Hispanic White people, then divided by the national overall mean. Mean values are population-weighted. States displayed in white indicate that the disparity is within $\pm 5 \%$ of the national overall mean. Purple shading indicates that mean exposures are higher-than-average by more than $5 \%$ of the national overall mean (columns 1-4) or that mean exposures are higher for racial-ethnic minorities than for the racial-ethnic majority, by more than $5 \%$ of the national overall mean (column 5). Orange shading indicates the reverse: mean exposures are lower-than-average for that group (columns 1-4) or mean exposures are lower for racial-ethnic minorities than for non-Hispanic White people (column 5), and the disparity is greater than $5 \%$ of the national overall mean. "NH" refers to non-Hispanic. "Hispanic" refers to Hispanic people of any race(s).

\section{Supplemental Material}

Supplementary material are available online.

\section{Acknowledgments:}

Funding: This publication was developed as part of the Center for Air, Climate, and Energy Solutions (CACES), which was supported under Assistance Agreement No. R835873 awarded by the U.S. Environmental Protection Agency. It has not been formally reviewed by EPA. The views expressed in this document are solely those of authors and do not necessarily reflect those of the Agency. EPA does not endorse any products or commercial services mentioned in this publication. Author contributions: J.L. conducted the research and most of the analysis, developed the methods, visualized the data, and wrote, reviewed, and edited the text. M.B. and L.P.C. designed the research, performed the research, analyzed the data, and wrote, reviewed, and edited the text. A.H., SY.K., A.L.R., L.S., and A.A.S. conceptualized and designed the research, oversaw the methods and analysis, and reviewed and edited the writing. J.D.M. conceptualized and supervised the project, designed the research, methods, and analysis, and wrote, reviewed, and edited the text. A.L.R. and J.D.M. acquired the funding. Competing interests: The authors declare no competing interests. Data and material availability: All data used are publicly available. Demographic data are available via IPUMS National Historic Geographic Information Systems [www.nhgis.org]; air pollution estimates are available via the EPA CACES project [www.caces.us]).

990

991 The authors thank Kristin Harper, of Harper Health \& Science Communications, LLC, for providing editorial support in accordance with Good Publication Practice (GPP3) guidelines. We also thank the CACES science advisory committee (SAC) for feedback on earlier versions of this research. 
992

993

994 